\title{
ИЗУЧЕНИЕ СВОЙСТВ МАРГАНЦА В МИКРО И НАНОСТРУКТУРАХ
}

\section{STUDY OF THE PROPERTIES OF MANGANESE IN MICRO AND NANOSTRUCTURES}

\author{
Тянь Ифань, Ван Шэнья
}

Национальный исследовательский Томский политехнический университет (пр-кт Ленина, 30, Томск, Томская обл., 634050)

Tian Yifan, Wang Shengya

National Research Tomsk Polytechnic University (Lenin Ave., 30, Tomsk, Tomsk Region, 634050)

e-mail: $916683237 @ q q . c o m$

Резюме: Статья посвящена сравнительному анализу Мn в обоих микро- и наноструктур: типа и параметр решетки прямая типа ОЦК, обратная типа ГЦК. Показано, что кристалл марганца имеет поверхность Ферми , реальная поверхность Ферми имеет не сферическую форму и свойства Мn в микро- и наноструктуры существенно отличаются. При рассматриваемом размере наноструктуры $\mathrm{Mn}$ (размер которой лежит в диапазоне от 20 до 30 нм) основное влияние на изменение свойств Мn оказывает классический размерный эффект. Эти результаты были подтверждены путем сравнения размера порошка $\mathrm{Mn}$ с длиной волны де Бройля электрона в наноструктуры Mn. Физические причины изменены в свойствах наноструктуры никеля. В конце описывается технология получения и анализируется влияние материалов марганца на окружающую среду. Различные морфологии наноматериалов оксида марганца обладают многими особыми физико-химическими свойствами, которые показывают их широкие перспективы применения в каталитических материалах, катодных материалах для литиево-ионных вторичных батарей и новых магнитных материалов. С быстрым развитием современного общества экологические проблемы все больше привлекают внимание.

Ключевые слова: Тип решетки и параметры марганца, зона Бриллюэна, поверхность Ферми, классический размерный эффект, Нанопорошок, зона Бриллюэна.

Summary: The article is devoted to the comparative analysis of Mn in both micro- and nanostructures: the type and the lattice parameter of the straight line of the bcc type, the inverse of the fcc type. It is shown that a manganese crystal has a Fermi surface, the real Fermi surface has a non-spherical shape. and the properties of Mn in micro and nanostructures are significantly different. With the considered size of the Mn nanostructure (the size of which lies in the range from 20 to $30 \mathrm{~nm}$ ), the classical size effect has the main influence on the change in the properties of Mn. These results were confirmed by comparing the size of the Mn powder with the electron de Broglie wavelength in the Mn nanostructures. Physical causes are altered in the properties of nickel nanostructures. At the end, the production technology is described and the impact of manganese materials on the environment is analyzed. Different morphologies of manganese oxide nanomaterials have many special physicochemical properties, which show their wide prospects for use in catalytic materials, cathode materials for lithium-ion secondary batteries and new magnetic materials. With the rapid development of modern society, environmental issues are increasingly attracting attention.

Keywords: Lattice type and manganese parameters, Brillouin zone, Fermi surface, classical size effect, Nanopowder, Brillouin zone.

\section{Введение}

Марганец - элемент побочной подгруппы седьмой группы четвёртого периода периодической системы химических элементов Д . И. Менделеева с атомным номером 25. Обозначается символом Mn (лат. Manganum, ма́нганум, в составе формул по-русски читается как марганец, например, $\mathrm{KMnO}_{4}$ — калий марганец о четыре). Простое вещество марганец — металл серебристо-белого цвета. Наряду с железом и его сплавами относится к чёрным металлам. Известны пять аллотропных модификаций марганца — четыре с кубической и одна с тетрагональной кристаллической решёткой. 


\section{Тип решетки и параметры марганца}

Марганец - элемент побочной подгруппы седьмой группы четвёртого периода периодической системы химических элементов Д. И. Менделеева с атомным номером 25.Обозначается символом Mn. Простое вещество марганец - металл серебристо-белого цвета[1]. Наряду с железом и его сплавами относится к чёрным металлам. Известны пять аллотропных модификаций марганца - четыре с кубической и одна с тетрагональной кристаллической решёткой[2].

Прямой: ОЦК

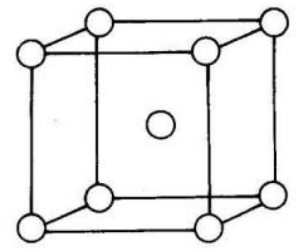

Рис1.Прямаяобъёмно-центрированная кубическая (ОЦК) решетка марганца. Прямая решетка с периодом а $=0.89125$ HM.
Обратной: ГЦК

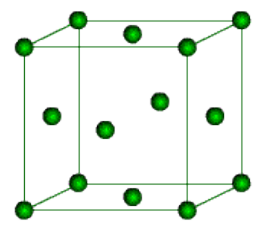

Рис. 2. Гранецентрированная кубическая (ГЦК) решетка Марганца. Обратная решетка Марганца(ГЦК) с параметром $\mathrm{a} *=\mathrm{a} \times 2 \pi$

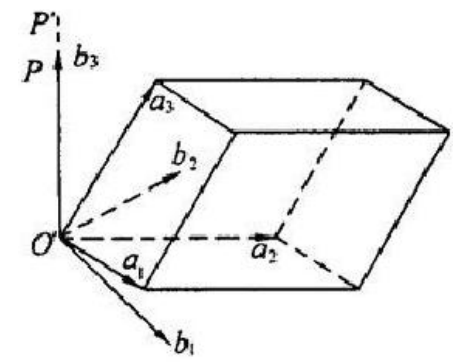

Рис. 3. Параметры решетки Марганец

\section{Зона Бриллюэна и поверхность Ферми}

В физике твердого тела первая зона Бриллюэна представляет собой однозначно определенную примитивную ячейку в обратном пространстве. Точно так же решетка Браве разделяется на ячейки Вигнера-Зейтца в реальной решетке, обратная решетка разбивается на зоны Бриллюэна[3]. Первая зона Бриллюэна марганец показана на рис.1.

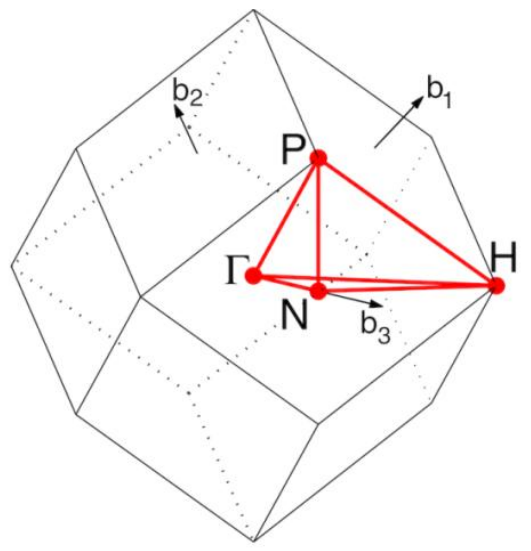


Рис 4. зона Бриллюэн

Кристалл марганца имеет поверхность Ферми как показано на рис 2. В большинстве случаев находясь внутри представляющей собой многогранник зоны Бриллюэна, реальная поверхность Ферми имеет не сферическую форму, которую имеет идеальная поверхность Ферми [4].

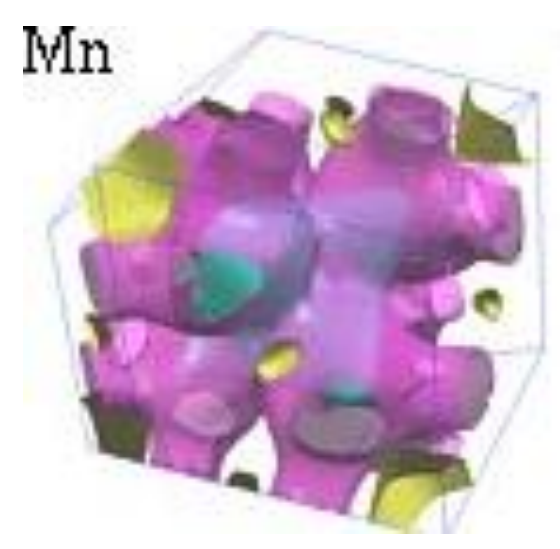

Рис 5. Поверхность Ферми внутри зоны Бриллюэна

Знание формы поверхности Ферми играет важную роль во всей физике металлов и вырожденных полупроводников, так как благодаря вырожденности электронного газа транспортные свойства его, такие как проводимость, магнетосопротивление зависят только от электронов вблизи поверхности Ферми.

В теории твердого тела энергия Ферми является одним из нескольких важных параметров кристалла. Энергия Ферми считаеться последующей формуле:

$$
\left\{\begin{array}{l}
E_{F}(0)=\frac{h^{2}}{2 m} \times\left(\frac{3 n}{8 \pi}\right)^{\frac{2}{3}}, \quad \text { при температуре } \mathrm{T}=0 \mathrm{~K} . \\
E_{F}=E_{F}(0) \times\left[1-\frac{\pi^{2}}{12} \times\left(\frac{k T}{E_{F}(0)}\right)^{2}\right], \text { при } \mathrm{T}>0 \mathrm{~K}(\mathrm{~T}=300 \mathrm{~K}) .
\end{array}\right.
$$

Концентрация электронов проводимости $n=\frac{Z \cdot \rho \cdot N_{A}}{M}$, где $\mathrm{Z}-$ число валентных электронов одного атома марганца, $\rho$ - плотность металла марганца, $\mathrm{M}$ - молярная масса марганца.

\section{Свойств Марганца в микро и наноструктурах}

Таблица свойств Марганца в макро и наноструктурах. В таблице 1 представлено сравнение свойстваМарганца в макро и наноструктурах.

Таблица 1. Свойств Марганца в макро и наноструктурах

\begin{tabular}{|c|c|c|c|c|}
\hline Свойства & Макро & Нано & $\begin{array}{c}\text { Размер } \\
(\text { нм })\end{array}$ & $\begin{array}{c}\text { Вид } \\
\text { наномодериала }\end{array}$ \\
\hline Плотность, г/см & 7.44 & 7.5 & 30 & Порошок \\
\hline Температура & 1517 & 1223 & 30 & Порошок \\
\hline
\end{tabular}




\begin{tabular}{|c|c|c|c|c|}
\hline плавления, K & & 1273 & 20 & \\
\hline Температура & 2235 & 1773 & 30 & Порошок \\
кипения, $\mathrm{K}$ & & 1873 & 20 & \\
\hline $\begin{array}{c}\text { Теплоемкость, J } \\
\text { (толь К) }\end{array}$ & 26.32 & & & \\
\hline $\begin{array}{c}\text { Электросопротивл } \\
\text { ение }\end{array}$ & 1,55 & & & \\
\hline
\end{tabular}

Согласно таблице плотность марганца в наноструктуре почти такая же, как плотность микроструктуры, но плотность наноструктуры несколько меньше плотности микроструктуры. Температура плавления и температура кипения микроскопических и наноструктур различны. Температура плавления наноструктур намного меньше точки плавления микроструктуры, нанометрический марганец размером 20 нм имеет температуру плавления, немного превышающую температуру нанометрового марганца 30 нм, а нанометровый марганец размером 20 нм имеет точку кипения, немного меньшую, чем нанометровая марганца на 30 нм.

\section{Размерный Эффект}

Появления необычных свойств наносистем вызываютклассический, или квантовый размерный эффект[5]. Если геометрический размер наноструктуры соизмерим с длиной свободного пробега носителей заряда, проявляется классический размерный эффект; если геометрический размер наноструктуры соизмерим с длиной волны де Бройля электрона, проявляется квантовый размерный эффект.

В наноструктурев атоме марганца, скорость движения электрона $v=1.1 \times 10^{6}$, масса электрона $\mathrm{m}=9.1 \times 10^{-31}$ кг, то длина волны де Бройля

$$
\lambda=\frac{h}{p}=\frac{h}{m v}=\frac{6.63 \times 10^{-34}}{9.1 \times 10^{-31} \times 1.1 \times 10^{6}}=0.66 \mathrm{\mu M}
$$

Порошок марганца размером D порядка 20 нм, очевидно из расчета, что $\lambda<<$ D. Так как длина волны де Бройля значительно меньше размеров наночастиц марганца, классический размерный эффект и приповерхностная зона оказывают основное влияние на изменение свойств нанопорошка марганца по сравнению с микроструктурой.

\section{Технология получения}

Оксиды марганца часто используются для изготовления наноматериалов, таких как двуокись марганца. Диоксид нано-марганца широко изучен как экологически чистый катализатор. Способы синтеза в основном включают гидротермический метод, метод твердофазного синтеза, золь-гель-метод, метод электрохимического осаждения и метод 
совместного осаждения. Различные способы получения оказывают различное влияние на распределение частиц по размерам, размер зерна и кристаллическую трансформацию диоксида марганца. Свойства, структура и морфология наномарганцевого диоксида имеют большую связь с методами приготовления и условиями приготовления. Для синтеза специфической структуры, морфологии и размера нанометрового диоксида марганца, необходимого для фактического производства или эксперимента, имеет большое практическое значение изучение метода синтеза нанометрового диоксида марганца.

В настоящее время одним из основных способов получения наноразмерногооксиды марганцаявляется гидротермальная подготовка нанометрового диоксида марганца.

Получение нанометрового диоксида марганца гидротермальным способом относится к способу формирования нанометрового диоксида марганца при высокой температуре и высоком давлении путем приготовления раствора в определенном соотношении в водном растворе. В гидротермальных условиях растворимость растворенных ионов возрастает, а активность ионов увеличивается, что позволяет осаждаться и перекристаллизовываться, зарождаться и растираться. Диоксид наномарганца, полученный гидротермальным методом, обладает высокой чистотой, хорошей диспергируемостью и легкостью получения контролируемых морфологических наночастиц[6][7].

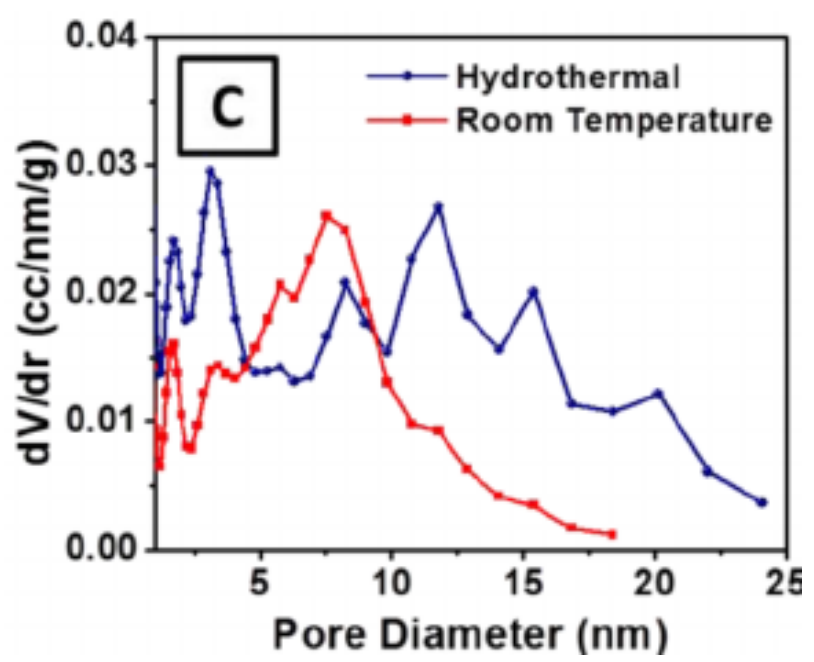

Рис.6 распределение пор по размерам для гидротермальной и комнатной температуры синтезированного оксида марганца.

\section{Применение}

Ресурсы марганца изобилуют ресурсами, низкими ценами, экологически чистыми и нетоксичными, а марганцевые материалы стали горячей точкой в последние годы. Однако обычные материалымарганцаимеют большой размер частиц, небольшую удельную площадь поверхности и несколько активных центров, которые ограничивают их химические свойства. Разработка наномагнетических марганцевых материалов является хорошим способом решения этих проблем. 
Различные морфологии наноматериалов оксида марганца обладают многими особыми физико-химическими свойствами, которые показывают их широкие перспективы применения в каталитических материалах, катодных материалах для литиево-ионных вторичных батарей и новых магнитных материалов. С быстрым развитием современного общества экологические проблемы все больше привлекают внимание. Также актуальной темой исследования является применение характеристик наноматериалов для каталитической деградации загрязнителей окружающей среды[8].

\section{Список литературы}

[1] Michael E. Wieser, Norman Holden, Tyler B. Coplen, John K. Böhlke, Michael Berglund, Willi A. Brand, Paul De Bièvre, Manfred Gröning, Robert D. Loss, Juris Meija, Takafumi Hirata, Thomas Prohaska, Ronny Schoenberg, Glenda O’Connor, Thomas Walczyk, Shige Yoneda, Xiang-Kun Zhu. Atomic weights of the elements 2011 (IUPAC Technical Report) (англ.) // Pure and Applied Chemistry. - 2013. - Vol. 85, no. 5. - P. 1047-1078. - DOI: 10.1351/PAC-REP13-03-02.

[2] Редкол.:Кнунянц И. Л. (гл. ред.). Химическая энциклопедия: в 5 т. - Москва: Советская энциклопедия, 1990. - Т. 2. - С. 647. - 671 с. - 100000 экз. В.В. Еремин и др. Химия. 10 класс. Профильный уровень. - Москва: Дрофа, 2008. - С. 166. - 463 с. - 7000 экз. ISBN 978-5-358-01584-5.

[3] Kittel, Charles (1996). Introduction to Solid State Physics. New York City: Wiley. ISBN $\underline{\text { 0-471- }}$ $\underline{14286-7}$

[4]Physical Material: Textbook for high schools: The 6 th ed. B. A. Kalyna. - M.: MIFI, 2007.

[5] O.N. Azarenkov, A.A. Veryovkin, G.P. Kovtun. Kosovo nanotechnologies and nanomaterials, $2009-69 p$.

[6]DuanYuping, Ms He, Li Xiaogang, et. al. Themicrowave electro-magnetic characteristics of manganese dioxide with different crystal-lographic structure $[\mathrm{J}]$. Physica B, 2012, 405: 18261831.

[7] Composite Manganese Oxide Percolating Networks As a Suspension Electrode for an Asymmetric Flow Capacitor in ACS Applied Materials \& Interfaces 6(11) · April [8]Preparation of Manganese Oxide Nanobelts[J];Journal of Materials Science \& Technology 